JOURNAL OF MECHANICAL ENGINEERING, MANUFACTURES, MATERIALS AND ENERGY

Doi: $10.31289 /$ jmemme.v5i2.5349

Available online http://ojs.uma.ac.id/index.php/jmemme

\title{
Simulasi Numerik Tentang Pengaruh Geometri Mandibula yang Direkonstruksi Terhadap Tegangan Von Mises
}

\section{Numerical Simulation on the Effect of Reconstructed Mandibular Geometry to von Mises Stress}

\author{
Rakhmad A. Siregar1)*, M. Yusuf Rahmansyah Siahaan²) dan Riki Juliansyah ${ }^{3}$ ) \\ ${ }^{1}$ Universitas Medan Area \\ 2 Universitas Muhammadiyah Sumatera Utara \\ Diterima: 06-06-2021 ; Disetujui: 17-07-2021 ; Diterbitkan: 30-12-2021 \\ *Corresponding author: E-mail: rakhmadarief@staff.uma.ac.id
}

\begin{abstract}
Abstrak
Studi tentang rekonstruksi mandibula diketahui sebagai tindakan yang paling menantang karena dagu yang cacat dapat menyebabkan seseorang memiliki harga diri yang rendah. Walaupun kemajuan teknologi medis sudah demikian maju selalu ada tren terbaru yang kaitannya dengan implan mandibula. Studi ini menginvestigasi pengaruh geometri mandibula yang direkonstruksi terhadap tegangan von Mises. Ada tiga model mandibula yang direkonstruksi berdasarkan lengkung gigi, square, ovoid dan tapered untuk mengamati distribusi tegangan von Mises. Ketiga model tersebut dikenakan tiga pembebanan yang bervariasi disekitar alveolar ridge untuk simulasikan aktifitas mengggit. Diperoleh hasil yang menunjukan faktor geometri berpengaruh terhadap distribusi tegangan von Mises, dimana mandibula dengan lengkung gigi tapered memberikan respon tegangan von Mises yang rendah dibanding model mandibula yang lain dan semakin berpegaruh signifikan bila beban yang diberikan semakin meningkat.
\end{abstract}

Kata Kunci: Analisis Elemen Hingga; Lengkungan Gigi; Rekonstruksi Mandibula; Pencetakan 3D

\begin{abstract}
The study of mandibular reconstruction is known to be the most challenging procedure because a deformed chin may result in a person having low self-esteem. Despite advances in medical technology, there are always new trends related to mandibular implants. This study investigates the effect of reconstructed mandibular geometry on von Mises stress. There are three reconstructed mandibular models based on dental arches, square, ovoid and tapered to observe the distribution of von Mises stress. The three models were subjected to three varying loads around the alveolar ridge to simulate biting activity. The results show that geometric factors affect the distribution of von Mises stress, where the mandible with a tapered dental arch shows lower von Mises stress response compared to other mandibular models and has a significant effect when the applied load increases.
\end{abstract}

Keywords: Finite Element Analysis; Dental Arch; Mandibular Reconstruction; 3D Printing

How to Cite: Siregar, R.A., 2021, Simulasi Numerik Tentang Pengaruh Geometri Mandibula yang Direkonstruksi Terhadap Tegangan Von Mises, JMEMME (Journal of Mechanical Engineering, Manufactures, Materials and Energy), 5 (02): 187-193. 


\section{PENDAHULUAN}

Kemajuan teknologi pencitraan tiga dimensi (3D) dalam perencanaan pembedah dengan bantuan komputer dan simulasi sekarang sangat membantu meningkatkan hasil bedah dalam bedah ortognatik. Teknologi Computed tomography (CT) dan rekonstruksi 3D pada tahun 1970-an berevolusi ke berbagai bidang kedokteran maupun teknik. Di akhir tahun 1990-an, seiring dengan perkembangan Personal Computer (PC), teknologi pencitraan 3D diperkaya dengan sistem osteotomi virtual 3D yang dapat merencanakan prosedur bedah ortognatik di PC yang Xia, dkk. namakan Computer-Assisted Osteotomi Virtual Sistem (CAVOS) [1]. CAVOS bekerja sebagai workbench secara virtual yang dapat memanipulasi data CT, membangun rekonstruksi tiga dimensi dari seluruh tengkorak dan menghasilkan visualisasi 3D dengan cepat. Software ini juga dapat melakukan operasi secara virtual melakukan beberapa osteotomi lingkungan realitas maya. Lin mereview penelitian tentang penggunaan metode pencetakan 3D dalam bedah ortognatik yang meliputi 3D CAD/CAM, pembuatan rapid prototipe, aditif manufaktur, pencetakan 3D, model cetak 3D, belat oklusal bedah hingga panduan yang dibuat khusus untuk tujuan tertentu [2]. Diakhir kesimpulannya disampaikan bahwa masih banyak potensi penelitian yang dapat dikembangkan di bidang ortognatik. Bedah untuk rekonstruksi mandibula dengan mengaplikasikan model 3D sebagai pedoman, dilaporkan mengurangi kegagalan paparan plat dan patah/rusak pada plat [3].

Rekonstruksi mandibula dilakukan dengan menggunakan pemotongan hasil CT, namun, teknik ini harus menggunakan perangkat lunak yang mahal. A. Dupret-Bories, $\mathrm{dkk}$, memberikan solusi dengan menggunakan freeware panduan pemotongan dan template mandibula cetak 3D yang dapat dikirim dalam 7 hari dan dengan biaya lebih rendah [5]. Perangkat lunak 3D Slicer Blender (freeware) digunakan untuk mengimport gambar 2D images hasil CT scan pasien dalam format DICOM (Digital Imaging and Communications in Medicine) dikompilasi untuk disusun kembali dalam tampilan 3D virtual yang kemudian diekspor dalam format STL untuk dioptimalkan (koreksi ketidaksempurnaan dan pembuatan dukungan ) sebelum pencetakan 3D. Hasil cetakan 3D dari mandibula PLA akan menjadi cetakan untuk plat titanium sebelum pembedahan seperti dalam hasil mereka yang ditampilkan ulang di Gambar 1.

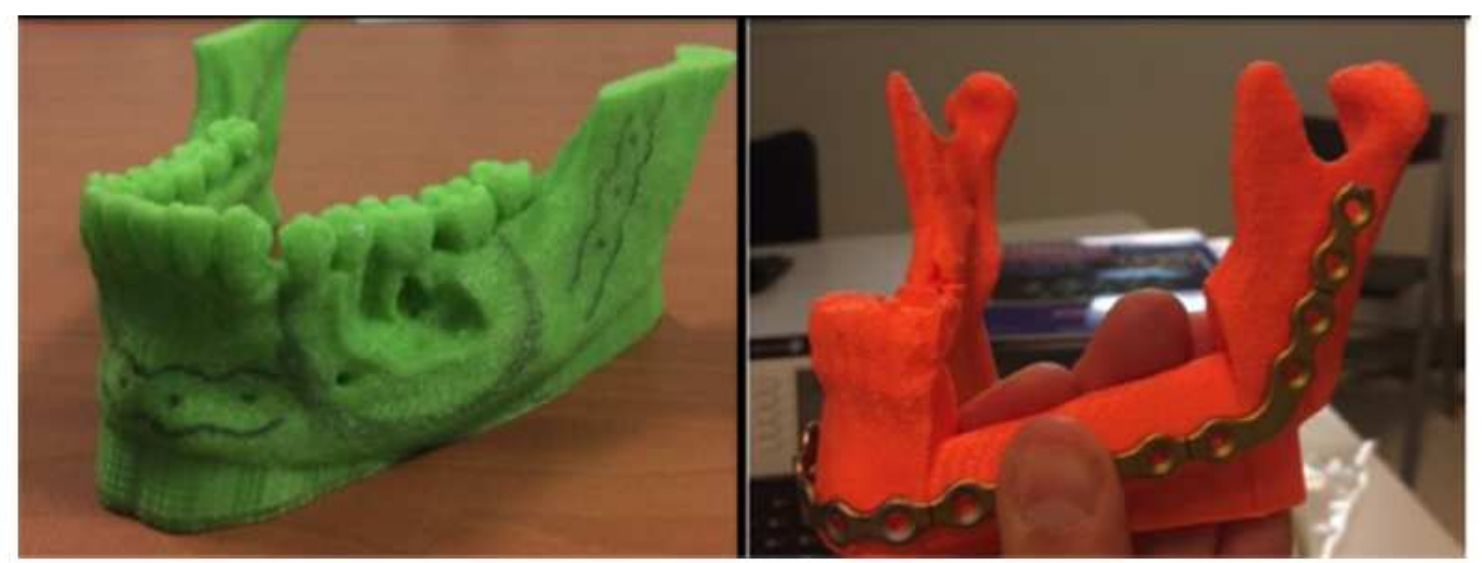

(a)

(b)

Gambar 1. (a) PLA Madibular (b) Plat Titanium mengikuti bentuk cetakan mandibular. 
Penggunaan campuran bahan bio untuk memperkuat struktur plat seperti banana stem memberikan hasil akhir yang menjanjikan [6]. Plat titanium yang mengikuti bentuk cetakan mandibula dapat disempurnakan dengan mencetak perancah prosthesis yang akan meningkatkan keberhasilan rekonstruksi mandibula yang sensitive terhadap estetika dan perilaku biomekanik. Implan yang dirancang khusus ini memberikan pilihan yang lebih baik untuk restorasi mandibula daripada plat titanium [7]. Impan khusus perancah (scaffolds) yang dirancang menggunakan teknologi EBM, memberikan tekstur permukaan yang kondusif untuk pertumbuhan jaringan membuatnya sesuai untuk implan yang dipersonalisasi dengan sifat yang lebih dekat dengan tulang. Dua perancah digunakan dalalam kajian mereka berdasarkan pelat berpori bagian dalam serta bagian atas dan bawah pelat berpori yang dianalisis secara numerik menggunakan perangkat lunak Finite Element Analysis (FEA).

Penggunaan teknologi AM (Additive Manufacturing) untuk implan medis, pembahasan konsentrasi tegangan pada plat, pegaruh laju regangan dan simulasi numerik telah dikaji sebelumnya [8-11]. Dalam studi ini, kajian numerik terhadap mandibula yang geometrinya berasal dari tiga lengkungan gigi, square, ovoid dan tapered. Kajian faktor geometri terhadap deformasi dan tegangan pada mandibula masih belum banyak dilakukan. Tiga bentuk mandibular digambar ulang dengan menggunakan software solidworks. Dengan menggunakan data tipikal untuk tiga bentuk geometry mandibula, diberikan pembebanan statis 3, 4, dan $5 \mathrm{~kg}$ disekitar alveolar ridge untuk mengamati tegangan efektif (von Misses) yang terjadi.

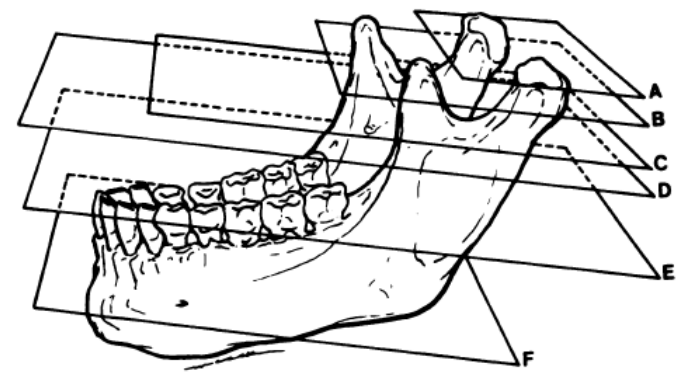

(a)

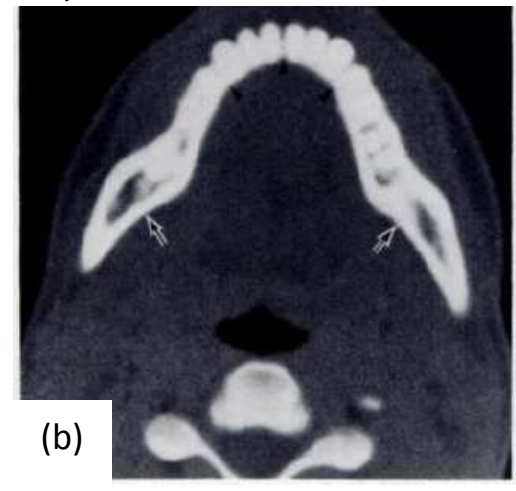

Gambar 2. CT Scan mandibula: (a) Sketsa mandibula disartikulasi dengan bidang CT (b) Bidang E hasil CT scan aksial melalui tubuh mandibula (panah) dan alveolan ridge (panah).

\section{METODE PENELITIAN}

Tiga geometri mandibula berdasarkan lengkung gigi, square, ovoid dan tapered digunakan dalam penelitian ini. Bentuk mandibula sederhana digambar dengan menggunakan solidworks dengan mengamati anatomi manibula hasil CT Scan [12] yang sebagian ditampilkan ulang dalam Gambar 2. Dimensi manibula diukur berdasarkan karakteristik morfologi [13], Gambar 3, untuk pasien edentulus penuh di RSGM USU [14], seperti ditunjukkan dalam Tabel 1. Tiga pembebanan statis diberikan 3, 4, dan $5 \mathrm{~kg}$ disekitar alveolar ridge untuk mengamati tegangan efektif (von Misses) pada setiap 
Rakhmad A. Siregar, Simulasi Numerik Tentang Pengaruh Geometri...

model mandibula. Simulasi statis menggunakan sifat bahan sebagai sifat bahan tulang yaitu elastis modulus $E=14,7 \mathrm{GPa}$ dan massa jenis $\rho=1900 \mathrm{~kg} / \mathrm{m}^{3}$ [15].

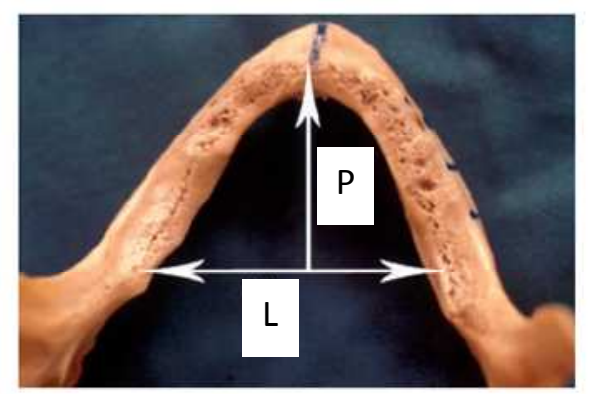

Gambar 3. Dimensi mandibula yang diukur.

Tabel 1. Dimensi Mandibula yang digunakan.

\begin{tabular}{cccc}
\hline Bentuk Struktur Gigi & $\begin{array}{c}\text { Panjang (P) } \\
(\mathbf{m m})\end{array}$ & $\begin{array}{c}\text { Lebar (L) } \\
\mathbf{( m m})\end{array}$ & $\begin{array}{c}\text { Tinggi (T) } \\
(\mathbf{m m})\end{array}$ \\
\hline Square & 112,5 & 97,1 & 84,1 \\
Ovoid & 112,4 & 95,1 & 82,1 \\
Tapered & 112,6 & 94,0 & 84,0 \\
\hline
\end{tabular}
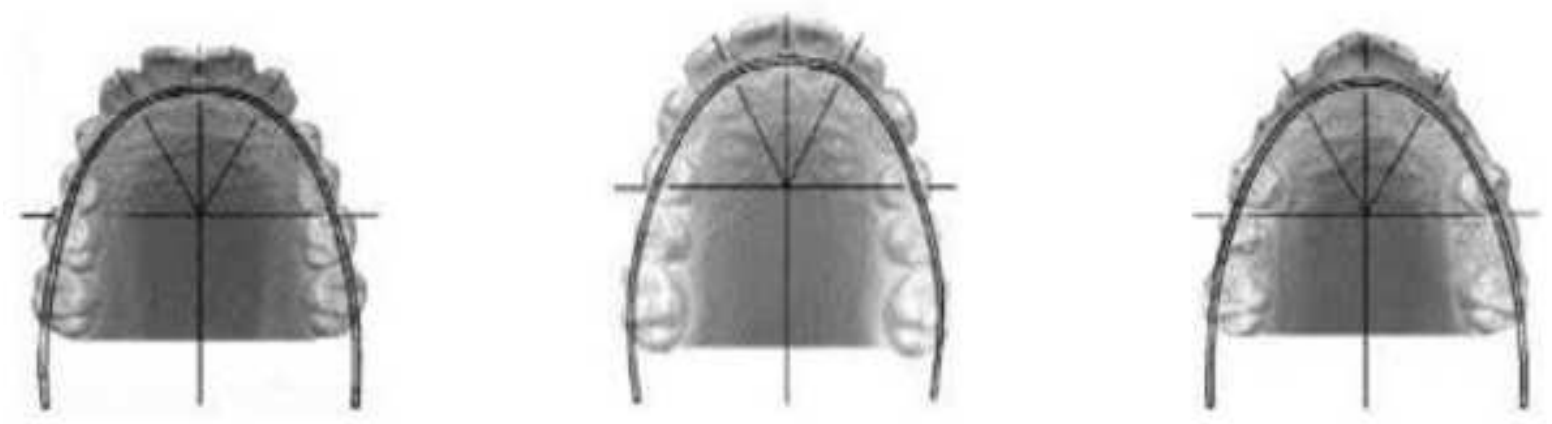

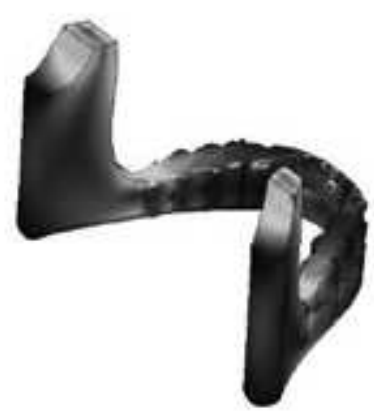

(a)

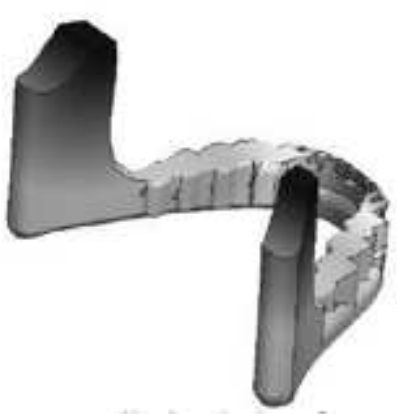

(b)

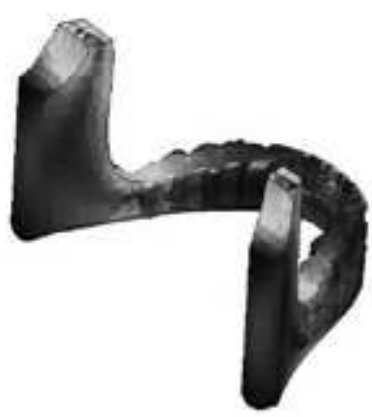

(c)

Gambar 3. Hasil Gambar ulang geometri mandibula menggunakan Solidoworks: (a) square, (b) Ovoid, dan (c) tapered 


\section{HASIL DAN PEMBAHASAN}

Dengan menggunakan data geometri pada Tabel 1, tiga model mandibula berhasil digambar seperti diperlihatkan dalam Gambar 4. Gambar 5, memperlihatkan proses pencetakan mandibular dengan menggunakan 3D printer. Gambar (a) dan (b) adalah hasil gambar ulang sederhana menggunakan solidworks yang kemudian ditransfer ke Ultimaker untuk menyiapkan model 3D dalam pencetakan 3D seperti dalam Gambar (c). Printer 3D yang digunakan adalah Printer 3D ANET A8 diperlihatkan pada Gambar (d) sedangkan Gambar (e) adalah hasil cetakan mandibula.

Simulasi dalam SOLIDWORKS yang menggunakan metode FEA digunakan sebagai alat untuk mengamati distribusi tegangan. Gambar 5, menunjukkan distribusi tegangan von mises pada mandibula square. Tegangan von Mises tertinggi didata dan diperlihatkan dalam Gambar 6 untuk model mandibula tiga struktur gigi. Berdasarkan bentuk geometri mandibular pembebanan tertinggi memberikan respon tegangan von Misses yang tinggi. Bila pembebanan dengan $\mathrm{F}=29,4 \mathrm{~N}$ dijadikan referensi, terjadi peningkatan sebesar 29\% pada pembebanan $\mathrm{F}=39,2 \mathrm{~N}$, tetapi melonjak tinggi hingga sekitar $150 \%$ untuk pembebanan $\mathrm{F}=49,0 \mathrm{~N}$. Hal ini menjadi fakta faktor geometri berpengaruh terhadap distribusi tegangan von Mises. Ketiga model memberikan informasi bahwa mandibula dengan struktur gigi tapered memberikan respon tegangan von Mises yang rendah dibanding model mandibular yang lain dan semakin berpegaruh signifikan bila beban yang diberikan semakin meningkat.

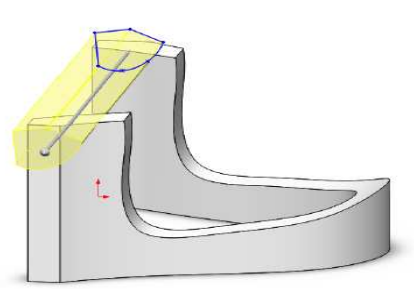

(a)

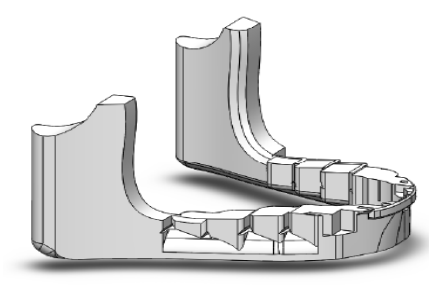

(b)

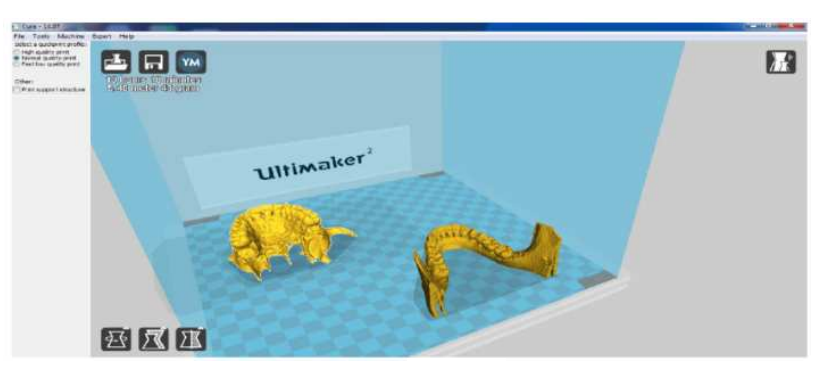

(c)

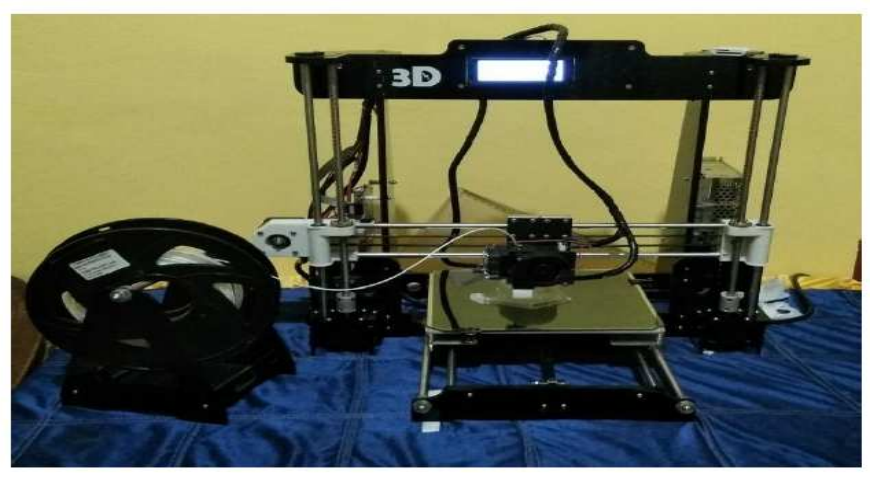

(d)

(e)

Gambar 4. Pembuatan model madibula dengan menggunakan pencetakan 3D: (a) gambar awal, (b) pembuatan gigi, (c) convert to 3D, (d) pencetakan 3D, dan (e) hasil 
Rakhmad A. Siregar, Simulasi Numerik Tentang Pengaruh Geometri...

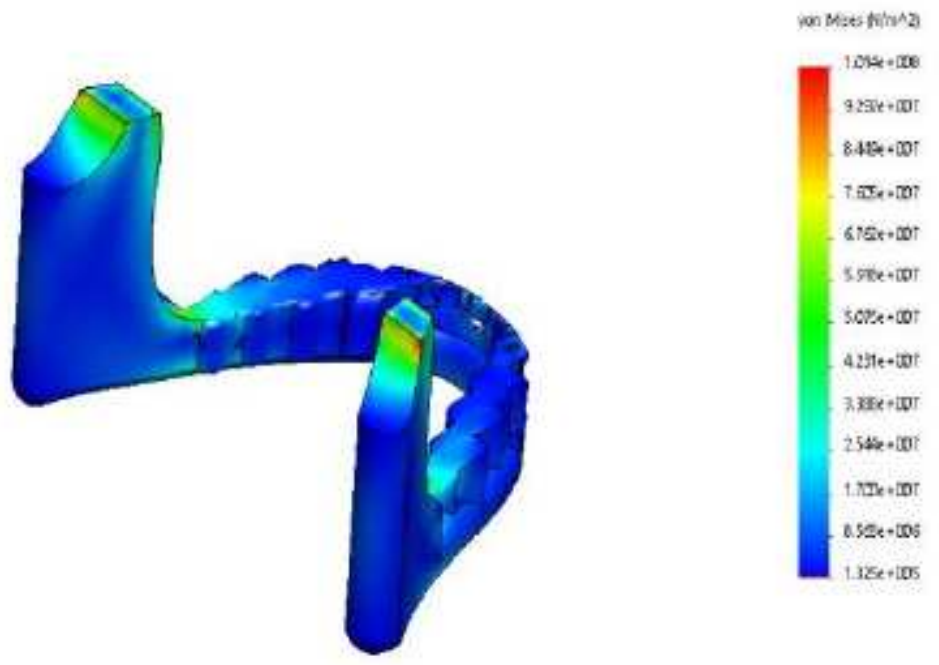

Gambar 5. Distribusi tegangan von mises pada mandibular square.

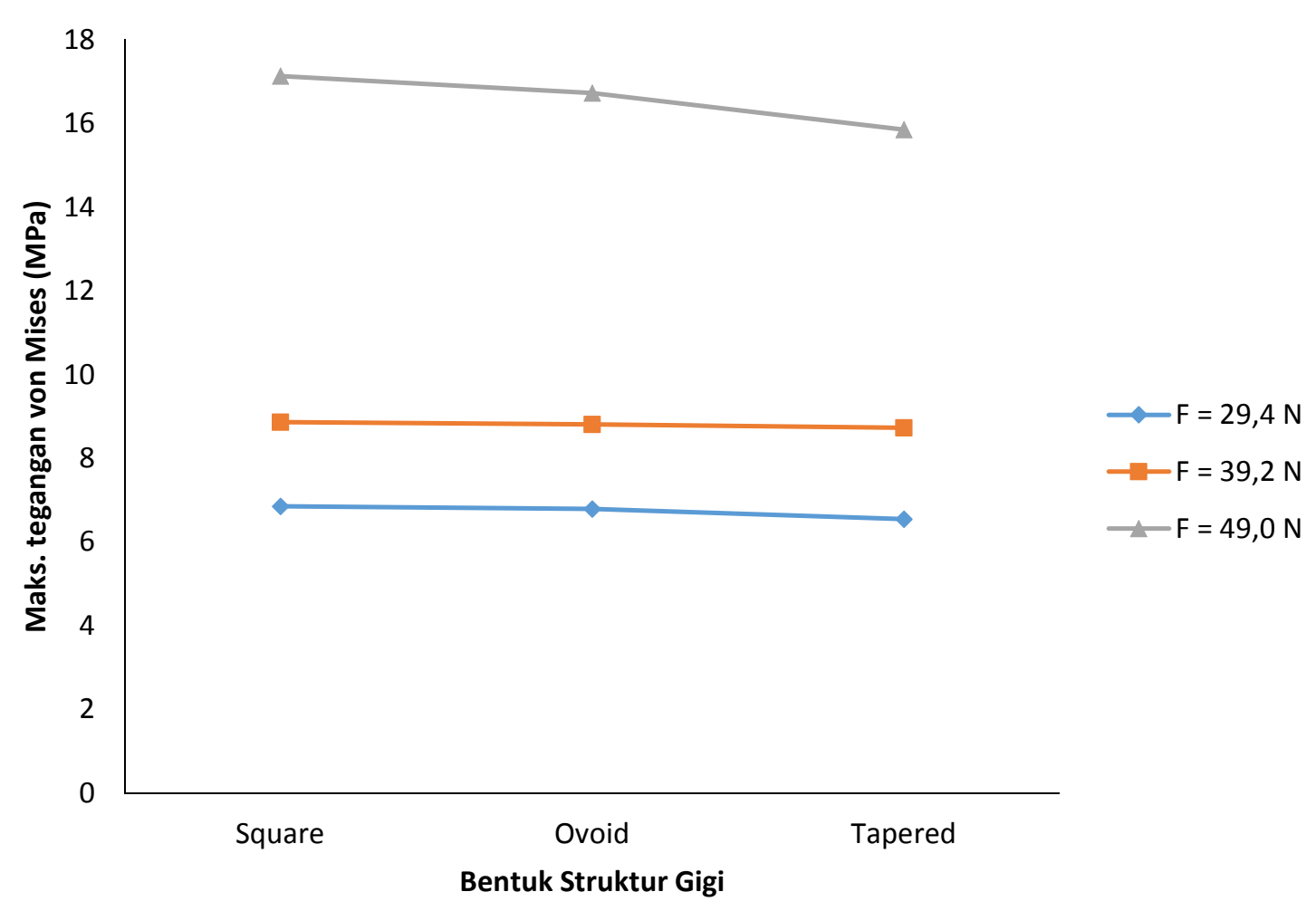

Gambar 6. Maksimum tegangan von Misses untuk tiga model mandibula.

\section{KESIMPULAN}

Rekonstruksi mandibula memberikan tantangan tersendiri disebabkan bentuk mandibular yang 3D dan kompleks disebabkan bentuk struktur gigi. Penerapkan model 
3D dari mandibula yang diproduksi menggunakan teknologi pencetakan tiga dimensi memungkinkan untuk mendapatkan hasil fungsional yang lebih baik. Dalam analisis numerik pada tiga model mandibula diperoleh hasil yang menunjukan faktor geometri berpengaruh terhadap distribusi tegangan von Mises.

\section{REFERENSI}

[1] James Xia, Horace H.S. Ip, Nabil Samman, Dongfeng Wang, Christy S.B. Kot, Richie W.K. Yeung, Henk Tideman, Computer-assisted three-dimensional surgical planning and simulation: $3 \mathrm{D}$ virtual osteotomy, International Journal of Oral and Maxillofacial Surgery, Volume 29, Issue 1, 2000, Pages 11-17.

[2] Lin HH, Lonic D, Lo LJ. 3D printing in orthognathic surgery - A literature review. J Formos Med Assoc. 2018 Jul;117(7):547-558.

[3] Mohammad Adhitya Latief, Benny S Latief, Lilies D S, the role of 3 d model as surgical guidance in mandibular reconstruction surgery, Jurnal Ilmiah dan Teknologi Kedokteran Gigi FKG UPDM (B) $\mathrm{Vol}$ 16, No 22020.

[4] Dupret-Bories A, Vergez S, Meresse T, Brouillet F, Bertrand G. Contribution of 3D printing to mandibular reconstruction after cancer. Eur Ann Otorhinolaryngol Head Neck Dis. 2018 Apr;135(2):133-136.

[5] Anne G. Osbonn, William H. Hanafee, and Anthony A. Mancuso, Normal and Pathologic CT Anatomy of the Mandible, AJR 139:555-559, September 1982.

[6] A.J. Zulfikar, B. Umroh, and M. Y. R. Siahaan, 2019, "Design and manufacture of skateboard from banana stem," JMEMME (Journal of Mechanical Enggineering, Manufactures, Materials and Energy), vol. 3, no. 2, pp. 109-116.

[7] Khaja Moiduddin, Syed Hammad Mian, Hisham Alkhalefah and Usama Umer, Digital Design, Analysis and 3D Printing of Prosthesis Scaffolds for Mandibular Reconstruction, Metals 2019, 9, 569.

[8] S.F. Khan, K. W. Dalgarno, R. A. Siregar, "Indirect Additive Manufacturing (AM) of ApatiteWollastonite (A-W) Glass-Ceramic for Medical Implants", Applied Mechanics and Materials, Vol. 786, pp. 354-36o, Aug. (2015).

[9] Rakhmad Arief Siregar, Khairul Umurani, Rahmatullah, Cahyo, Pengaruh Diameter Lubang Pada Faktor Konsentrasi Tegangan Untuk Plat Isotropis, Jurnal RMME, Vol 2, No. 1 (2019).

[10] Siregar R. A., Daimaruya, M., Kobayashi, H., and Shimada H., Strain rate effect on impact tensile stress of concretes by method of reflected tensile stress waves, J. Japan Exp. Mech., Vol. 4, No. 3, pp. 56-61 (2004).

[11] A.J. Zulfikar, A. Sofyan and M. Y. R. Siahaan, 2018, Numerical Simulation on The Onion Dryer Frame Capacity of $5 \mathrm{~kg} /$ hour, JMEMME (Journal of Mechanical Engineering Manufactures Materials and Energy), vol. 2, no. 2, p. 86-92.

[12] Osborn AG, Hanafee WH, Mancuso AA. Normal and pathologic CT anatomy of the mandible. AJR Am J Roentgenol. 1982 Sep;139(3):555-9. doi: 10.2214/ajr.139.3·555. PMID: 6981323.

[13] Pietrokovski J, Starinsky R, Arensburg B, Kaffe I. Morphologic Characteristics of Bony Edentulous Jaws. J Pros 2007; vol.16, No.2: 141-7.

[14] Tasya Estu Hidayana, Skripsi: Distribusi dan frekuensi bentuk dan ukuran lengkung rahang atas serta rahang bawah pada model studi pasien edentulus penuh di rsgm usu, Fakultas Kedokteran Gigi Universitas Sumatera Utara, Medan 2018.

[15] Cameron, John R.; James G. Skofronick \& Roderick M. Grant. Physics of the Body. Second Edition. Madison, WI: Medical Physics Publishing, 1999: 96. 